\title{
GENERALIZED WEIGHTED COMPOSITION OPERATORS FROM BERS-TYPE SPACES INTO BLOCH-TYPE SPACES
}

\begin{abstract}
XIANGLING ZHU
Abstract. New criteria for the boundedness and the compactness of the generalized weighted composition operators from Bers-type spaces into Bloch-type spaces are given in this paper.

Mathematics subject classification (2010): Primary 47B33, Secondary 30H30.

Keywords and phrases: Generalized weighted composition operators, Bers-type space, Bloch-type
\end{abstract} space.

\section{REFERENCES}

[1] F. Colonna And S. LI, Weighted composition operators from the Besov spaces to the Bloch spaces, Bull. Malaysian Math. Sci. Soc., to appear.

[2] F. Colonna AND S. LI, Weighted composition operators from Hardy spaces into logarithmic Bloch spaces, J. Funct. Spaces Appl., Vol. 2012, Article ID 454820, 20 pages.

[3] C. C. Cowen and B. D. MacCluer, Composition Operators on Spaces of Analytic Functions, Studies in Advanced Mathematics, CRC Press, Boca Raton, 1995.

[4] X. FU AND X. ZHU, Weighted composition operators on some weighted spaces in the unit ball, Abstr. Appl. Anal. 2008 (2008), Article ID 605807, 8 pages.

[5] D. GU, Weighted composition operators from generalized weighted Bergman spaces to weighted-type space, J. Inequal. Appl. 2008 (2008), Article ID 619525, 14 pages.

[6] W. He And L. JiAng, Composition operator on Bers-type spaces, Acta Math. Sci. 22B, 3 (2002), 404-412.

[7] R. A. HibsChweIler AND N. PorTnOy, Composition followed by differentiation between Bergman and Hardy spaces, Rocky Mountain J. Math. 35, 3 (2005), 843-855.

[8] S. Li AND S. STEVIĆ, Weighted composition operators from Bergman-type spaces into Bloch spaces, Proc. Indian Acad. Sci. Math. Sci. 117 (2007), 371-385.

[9] S. Li And S. STEvić, Composition followed by differentiation between Bloch type spaces, J. Comput. Anal. Appl. 9 (2007), 195-205.

[10] S. Li AND S. STEvić, Generalized composition operators on Zygmund spaces and Bloch type spaces, J. Math. Anal. Appl. 338 (2008), 1282-1295.

[11] S. Li AND S. STEVIĆ, Weighted composition operators from Zygmund spaces into Bloch spaces, Appl. Math. Comput. 206, 2 (2008), 825-831.

[12] S. Li AND S. STEVIĆ, Composition followed by differentiation from mixed-norm spaces to $\alpha$-Bloch spaces, Sb. Math. 199, 12 (2008), 1847-1857.

[13] S. Li AND S. Stević, Composition followed by differentiation between $H^{\infty}$ and $\alpha$-Bloch spaces, Houston J. Math. 35 (2009), 327-340.

[14] Z. Lou, Composition operators on Bloch type spaces, Analysis (Munich) 23 (2003), 81-95.

[15] K. Madigan And A. Matheson, Compact composition operators on the Bloch space, Trans. Amer. Math. Soc. 347 (1995), 2679-2687.

[16] S. Ohno, K. Stroethoff And R. Zhao, Weighted composition operators between Bloch-type spaces, Rocky Mountain J. Math. 33 (2003), 191-215.

[17] S. STEVIĆ, Weighted composition operators between mixed norm spaces and $H_{\alpha}^{\infty}$ spaces in the unit ball, J. Inequal. Appl. 2007 (2007), Article ID 28629, 9 pages. 
[18] S. STEVIĆ, Generalized composition operators between mixed norm space and some weighted spaces, Numer. Funct. Anal. Optimization 29 (2008), 959-978.

[19] S. STEVIĆ, Norm and essential norm of composition followed by differentiation from $\alpha$-Bloch spaces to $H_{\mu}^{\infty}$, Appl. Math. Comput. 207 (2009), 225-229.

[20] S. STEviĆ, Products of composition and differentiation operators on the weighted Bergman space, Bull. Belg. Math. Soc. Simon Stevin 16 (2009), 623-635.

[21] S. STEVIĆ, Weighted differentiation composition operators from mixed-norm spaces to weighted-type spaces, Appl. Math. Comput. 211 (2009), 222-233.

[22] S. STEVIĆ, Weighted differentiation composition operators from mixed-norm spaces to the $n$th weighted-type space on the unit disk, Abstr. Appl. Anal. 2010 (2010), Article ID 246287, 15 pages.

[23] S. STEVIĆ, Weighted iterated radial composition operators between some spaces of holomorphic functions on the unit ball, Abstr. Appl. Anal. 2010 (2010), Article ID 801264, 14 pages.

[24] S. STEvić, Composition followed by differentiation from $H^{\infty}$ and the Bloch space to $n$th weightedtype spaces on the unit disk, Appl. Math. Comput. 216 (2010), 3450-3458.

[25] S. STEvić, Weighted differentiation composition operators from $H^{\infty}$ and Bloch spaces to $n$th weigthed-type spaces on the unit disk, Appl. Math. Comput. 216 (2010), 3634-3641.

[26] S. STEVIĆ, On a product-type operator from Bloch spaces to weighted-type spaces on the unit ball, Appl. Math. Comput. 217 (2011), 5930-5935.

[27] S. STEVIĆ, Characterizations of composition followed by differentiation between Bloch-type spaces, Appl. Math. Comput. 218 (2011), 4312-4316.

[28] S. Stević AND A. K. Sharma, Iterated differentiation followed by composition from Bloch-type spaces to weighted BMOA spaces, Appl. Math. Comput. 218 (2011), 3574-3580.

[29] S. Stević, A. K. Sharma And A. Bhat, Essential norm of products of multiplication composition and differentiation operators on weighted Bergman spaces, Appl. Math. Comput. 218 (2011), 23862397.

[30] M. WANG AND Y. LiU, Weighted composition operator between Bers-type spaces, Acta Math Sci 27A, 4 (2007), 665-671.

[31] Y. WU AND H. Wulan, Products of differentiation and composition operators on the Bloch space, Collect. Math. 63 (2012), 93-107.

[32] W. YANG, Weighted composition operators from Bloch-type spaces to weighted-type spaces, Ars Combin. 92 (2009), 415-423.

[33] W. YANG, Products of composition and differentiation operators from $\mathscr{Q}_{K}(p, q)$ spaces to Bloch-type spaces, Abstr. Appl. Anal. 2009 (2009), Article ID 741920, 14 pages.

[34] K. ZHU, Bloch type spaces of analytic functions, Rocky Mountain J. Math. 23, 3 (1993), 1143-1177.

[35] X. ZHU, Products of differentiation, composition and multiplication from Bergman type spaces to Bers type space, Integ. Tran. Spec. Funct. 18, 3 (2007), 223-271.

[36] X. ZHU, Generalized weighted composition operators from Bloch-type spaces to weighted Bergman spaces, Indian J. Math. 49 (2007), 139-149.

[37] X. ZHU, Generalized weighted composition operators on weighted Bergman spaces, Numer. Funct. Anal. Opt. 30 (2009), 881-893.

[38] X. ZHU, Weighted composition operators from $F(p, q, s)$ spaces to $H_{\mu}^{\infty}$ spaces, Abstr. Appl. Anal. 2009 (2009), Article ID 290978, 12 pages.

[39] X. ZHU, Generalized weighted composition operators on Bloch-type spaces, Ars Combin., to appear. 